\title{
Analisa Perawatan Berbasis Keandalan pada Sistem Bahan Bakar Mesin Utama kapal Motor Penyebrangan Bontoharu
}

\author{
Risna $^{* 1}$, Mohammad Lutfi ${ }^{2}$ \\ ${ }^{1,2}$ STT MIGAS, Balikpapan \\ *Imanuellrisna@yahoo.com
}

\begin{abstract}
Abstrak
Tujuan penelitian ini adalah untuk mengetahui komponen yang rawan terjadi dan nilai mean time to failure dari KMP. Bontobaharu. Metode yang digunakan dalam penelitan ini adalah analisis kualitatif yang meliputi failure mode, effect, analysis (FMECA), fault tree analysis (FTA) dan analisis kuantitatif menggunakan distribusi Weibull untuk mengetahui nilai mean time to failure (MTTF). Metode Risk Based Inspection and maintenance digunakan untuk mengetahui nilai resiko peralatan dan model penjadwalan perawatan, dan metode inspeksi yang digunakan berupa visual check. Hasil perhitungan dengan menggunakan distribusi Weibull mengungkapkan bahwa nilai MTTF filter adalah 194 jam, separator adalah 502 jam dan pipa adalah 2508 jam. Filter dan separator memiliki tingkat resiko paling tinggi, sedangkan tangki induk, tangka harian, pompa transfer, feed pompa, pompa injeksi dan injector service tank memiliki tingkat resiko menengah.
\end{abstract}

Kata kunci: sistem bahan bakar, keandalan, FMECA, FTA, perawatan

\begin{abstract}
This study determines the prone components and the mean time to failure of KMP. Bontobaharu. The method used in this research is the qualitative analysis, which comprises the failure mode, effect, analysis (FMECA), fault tree analysis (FTA), and quantitative analysis using Weibull distribution to determine the mean time to failure $(M T T F)$ value. The risk method based inspection and maintenance is used to determine the value of equipment risk and maintenance scheduling model, and the inspection method used is visual check. The results revealed that the value of MTTF filter was 194 hours, separator was 502 hours, and pipe was 2508 hours. Filters and separators have the highest level of risk, while the mainframe, daily trays, transfer pumps, feed pumps, injection pumps, and injector service tanks have medium risk levels.
\end{abstract}

Keywords: fuel system, reliability, FMECA, FTA, maintenance

\section{Pendahuluan}

Penggunaan analisa keandalan dalam industri perkapalan semakin meningkat sehubungan dengan kebutuhan akan kemanan dan keselamatan kapal yang handal [1].

Salah satu sistem layanan permesinan yang dipandang perlu dilakukan analisa adalah sistem bahan bakar motor induk. Sistem bahan bakar memegang peranan yang penting untuk menyuplai bahan bakar ke dalam ruang bakar pada motor diesel sebagai penggerak utama di kapal. Kegagalan pada komponen sistem bahan bakar dalam beroperasi diakibatkan dari gagalnya salah satu komponen yang ada pada sistem bahan bakar tersebut. Untuk itu diperlukan sebuah evaluasi keandalan untuk mencegah terjadinya kegagalan pada komponen tersebut.

Keandalan adalah probabilitas dari suatu item untuk dapat melaksanakan sebuah fungsi yang telah ditetapkan, pada kondisi pengoperasian dan lingkungan tertentu untuk periode waktu yang telah ditentukan [2]. 
Analisa keandalan terhadap komponenkomponen yang mendukung sistem di dalam kinerja bahan bakar tidak perlu menunggu terjadinya kegagalan terlebih dahulu, namun lebih mengutamakan untuk melakukan analisa keandalan sebagai langkah preventif untuk mencegah kegagalan itu sendiri.

Penelusuran pengaruh-pengaruh dari kegagalan komponen atau sistem dapat dilakukan dengan melakukan evaluasi dan analisa terhadap komponen-komponen atau sistem dengan menggunakan failure mode, effect, and analysis (FMECA) dan fault tree analysis (FTA), sehingga untuk meminimalkan resiko atau efek yang besar dari suatu tingkat kegagalan, maka manajemen resiko perlu dipertimbangkan sebagai metode untuk mendukung performansi suatu sistem.

Data kegagalan dan data perawatan yang telah dilakukan diolah untuk mendapatkan indeks keandalan, laju keandalan, nilai MTTF peralatan yang nantinya bermanfaat pada saat melakukan Analisa penentuan interval kegiatan perawatan [3].

Pendugaan distribusi merupakan langkah awal untuk menghitung mean time to failure (MTTF), indeks Keandalan $(\mathrm{R}(\mathrm{t}))$, dan laju kegagalan (Failure Rate) dari suatu komponen [4].

\section{Sistem Bahan Bakar}

Sistem penunjang motor induk dikapal berfungsi untuk membantu mesin induk agar beroperasi sesuai dengan fungsinya yaitu memberikan tenaga kepada propeller untuk mendorong kapal. Salah satu bagian dari sistem penunjang motor induk yaitu sistem bahan bakar [1].

Sistem bahan bakar kapal merupakan suatu sistem pelayanan untuk motor induk yang sangat vital. Sistem bahan bakar secara umum terdiri dari fuel oil supply, fuel oil purifying, fuel oil transfer dan fuel oil drain piping system. Sistem bahan bakar adalah suatu sistem yang digunakan untuk mensuplai bahan bakar dari bunker ke settling tank dan juga daily tank dan kemudian ke mesin induk atau mesin bantu. Adapun jenis bahan bakar yang digunakan di atas kapal bisa berupa heavy fuel oil (HFO), MDO, HSD ataupun solar, biasanya tergantung jenis mesin dan ukuran mesin. Untuk sistem yang menggunakan bahan bakar HFO untuk operasionalnya, sebelum masuk ke mesin utama HFO harus melalui treatment dahulu untuk penyesuaian viskositas, suhu, dan tekanan.

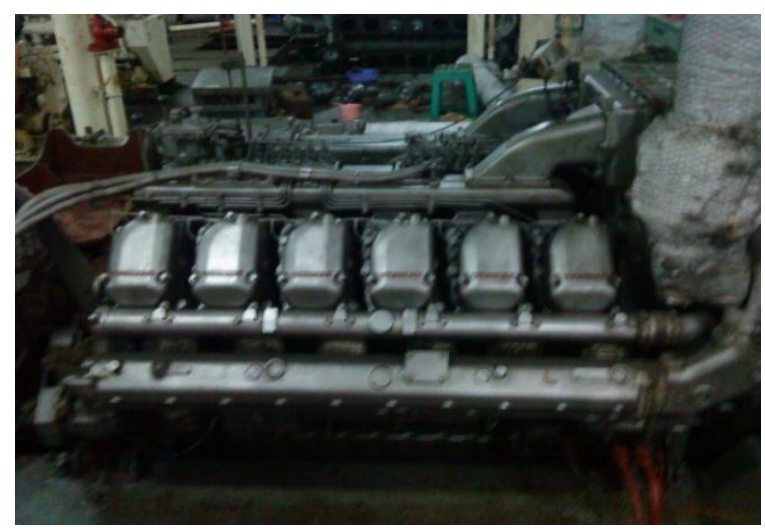

Gambar 1. Sistem Bahan Bakar Motor Induk KMP Bontobaharu

Gambar 1 memperlihatkan bahwa sistem bahan bakar motor induk KMP Bontoharu terbagi atas tiga fungsional sub sistem yaitu sub sistem pemompaan bahan bakar, sub sistem pembersihan bahan bakar, dan sub sistem penginjeksian bahan bakar.

Begitu pentingnya peran dari sistem penunjang motor induk tersebut, maka untuk dapat mendeteksi penyebab kegagalan komponen/sistem perlu dilakukan penelitian untuk mempelajari mengenai karakteristik pola kegagalan, pola perawatan serta kondisi operasional dari masing-masing komponen sistem bahan bakar. Dengan mempelajari mengenai dinamika sistem diharapkan dapat membantu menganalisa serta memahami suatu sistem yang kompleks berubah terhadap fungsi waktu [5].

\section{Analisa dan Pembahasan}

\subsection{Analisa Kualitatif}

FTAdigunakanuntuk mengindentifikasi semua akibat yang mungkin untuk terjadinya kegagalan sistem (Gambar 2). FTA berorientasi pada fungsi atau lebih dikenal dengan "top down approach" Tabel 1 sampai 
Tabel 7 mengidentifikasi mode-mode kegagalan, penyebab kegagalan, serta dampak kegagalan fungsi yang ditimbulkan oleh tiaptiap komponen dalam sistem bahan bakar KMP Bontoharu.

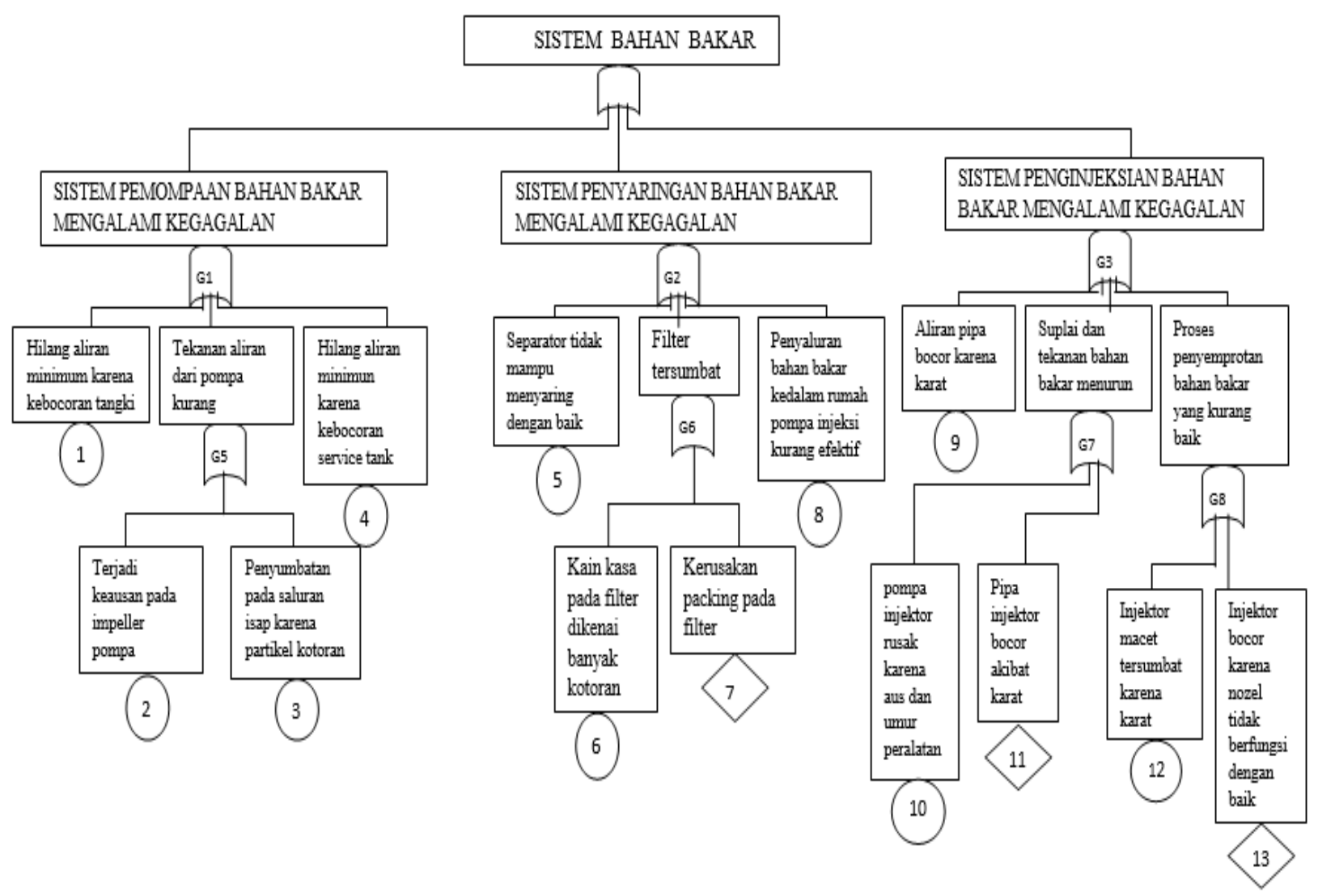

Gambar 2. Diagram Fault Tree FTA Sistem Bahan Bakar KMP. Bontoharu

Tabel 1. FMEA SubSistem Pemompaan Bahan Bakar

\begin{tabular}{|c|c|c|c|c|c|c|c|c|c|c|}
\hline \multirow{2}{*}{\multicolumn{2}{|c|}{$\begin{array}{c}\text { DESCRIPTION OF } \\
\text { UNI }\end{array}$}} & \multirow{3}{*}{ FUNCTION } & \multicolumn{3}{|c|}{ DESCRPTIONOF FAILURE } & \multicolumn{2}{|c|}{ EFFECT OF FAILURE } & \multirow{3}{*}{$\begin{array}{l}\text { FALURE } \\
\text { RATE }\end{array}$} & \multirow{3}{*}{$\begin{array}{l}\text { SEVERITY } \\
\text { RANGKING }\end{array}$} & \multirow{3}{*}{$\begin{array}{c}\text { RISK } \\
\text { REDUCTNG } \\
\text { MEASURES } \\
\end{array}$} \\
\hline & & & \multirow{2}{*}{$\begin{array}{l}\text { Failure } \\
\text { Mode }\end{array}$} & \multirow{2}{*}{\begin{tabular}{|c|} 
Failure \\
Mechanisme \\
\end{tabular}} & \multirow{2}{*}{$\begin{array}{c}\text { Detection of } \\
\text { Failure } \\
\end{array}$} & \multirow{2}{*}{ Local } & \multirow{2}{*}{ System } & & & \\
\hline $\mathbb{D}$ & Component & & & & & & & & & \\
\hline 20801 & $\begin{array}{l}\text { Tangki } \\
\text { Induk }\end{array}$ & $\begin{array}{l}\text { Tempat penampungan bahan } \\
\text { bakas untuk keperiluan mesin yang } \\
\text { terletalk pada double bottom }\end{array}$ & $\begin{array}{l}\text { Mengalami } \\
\text { kebocoran }\end{array}$ & Karat & $\begin{array}{l}\text { Diadakan } \\
\text { pemeriksaan } \\
\text { secara berkala } \\
\text { "setahun sekali" }\end{array}$ & $\begin{array}{l}\text { Fungsi } \\
\text { terganggu }\end{array}$ & $\begin{array}{l}\text { Suplai } \\
\text { bahan bakas } \\
\text { terganggu }\end{array}$ & Probable & Major & $\begin{array}{l}\text { Melalakukan } \\
\text { pemeriksaan pada } \\
\text { tempat-tempat } \\
\text { yang diduga dapat } \\
\text { mengakabatkan } \\
\text { kebocoran }\end{array}$ \\
\hline
\end{tabular}


Tabel 2. FMEA Sub Sistem Pemompaan Bahan Bakar

\begin{tabular}{|c|c|c|c|c|c|c|c|c|c|c|}
\hline \multirow{2}{*}{\multicolumn{2}{|c|}{$\begin{array}{c}\text { DESCRIPTION OF } \\
\text { UNT }\end{array}$}} & \multirow{3}{*}{ FUNCTION } & \multicolumn{3}{|c|}{ DESCRPTION OF FAILURE } & \multicolumn{2}{|c|}{ EFFECT OF FAILURE } & \multirow{3}{*}{$\begin{array}{l}\text { FAILURE } \\
\text { RATE }\end{array}$} & \multirow{3}{*}{$\begin{array}{l}\text { SEVERITY } \\
\text { RANGKING }\end{array}$} & \multirow{3}{*}{$\begin{array}{c}\text { RISK } \\
\text { REDUCTING } \\
\text { MEASURES }\end{array}$} \\
\hline & & & \multirow{2}{*}{$\begin{array}{l}\text { Failure } \\
\text { Mode }\end{array}$} & \multirow{2}{*}{\begin{tabular}{|c|} 
Failure \\
Mechanisme
\end{tabular}} & \multirow{2}{*}{$\begin{array}{c}\text { Detection of } \\
\text { Failure }\end{array}$} & \multirow{2}{*}{ Local } & \multirow{2}{*}{ System } & & & \\
\hline D & Component & & & & & & & & & \\
\hline \multirow[t]{2}{*}{20802} & \multirow[t]{2}{*}{$\begin{array}{l}\text { Pompa } \\
\text { Transfer }\end{array}$} & \multirow[t]{2}{*}{$\begin{array}{l}\text { Memindahkan bahan bakar dari } \\
\text { tangki induk ke tangki harian }\end{array}$} & $\begin{array}{l}\text { Keausan } \\
\text { pada impeller }\end{array}$ & $\begin{array}{l}\text { Diadakan } \\
\text { pemeriksaan } \\
\text { secara berkala }\end{array}$ & $\begin{array}{l}\text { Pompa tidak } \\
\text { beroperasi }\end{array}$ & $\begin{array}{l}\text { Fungsi } \\
\text { terganggu }\end{array}$ & Terganggu & Frequent & Major & $\begin{array}{l}\text { Diperlukan } \\
\text { perbaikan motor } \\
\text { agar dapat } \\
\text { menjalankan } \\
\text { fungsinya }\end{array}$ \\
\hline & & & $\begin{array}{l}\text { Penyumbatan pada } \\
\text { saluran isap }\end{array}$ & $\begin{array}{l}\text { Partikel } \\
\text { kotoran }\end{array}$ & $\begin{array}{l}\text { Diadakan } \\
\text { pemeriksaan } \\
\text { secara berkala }\end{array}$ & $\begin{array}{l}\text { Pompa tidak } \\
\text { berfungsi }\end{array}$ & Terganggu & Frequent & Major & $\begin{array}{l}\text { Saluran isap } \\
\text { dibersihkan } \\
\text { sehingga dalam } \\
\text { menyuplai } \\
\text { bahan bakar } \\
\text { dapat tersalurkan }\end{array}$ \\
\hline
\end{tabular}

Tabel 3. FMECA Sub Sistem Pemompaan Bahan Bakar

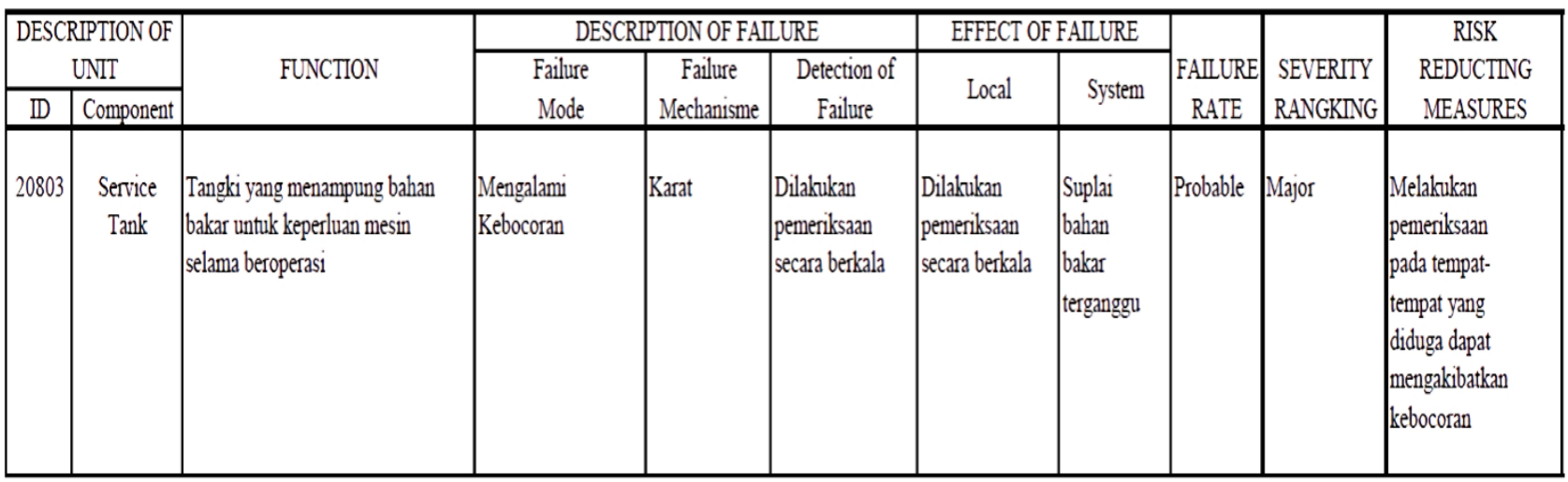

Tabel 4. FMECA Sub Sistem Penyaringan Bahan Bakar

\begin{tabular}{|c|c|c|c|c|c|c|c|c|c|c|}
\hline \multirow{2}{*}{\multicolumn{2}{|c|}{$\begin{array}{c}\text { DESCRPTIONOF } \\
\text { UNT } \\
\end{array}$}} & \multirow{3}{*}{ FUNCTION } & \multicolumn{3}{|c|}{ DESCRPPTON OF FAILURE } & \multicolumn{2}{|c|}{ EFFECT OF FALURE } & \multirow{3}{*}{$\begin{array}{l}\text { FAILURE } \\
\text { RATE }\end{array}$} & \multirow{3}{*}{$\begin{array}{l}\text { SEVERITY } \\
\text { RANGKING } \\
\end{array}$} & \multirow{3}{*}{$\begin{array}{c}\text { RISK } \\
\text { REDUCTING } \\
\text { MEASURES }\end{array}$} \\
\hline & & & \multirow{2}{*}{$\begin{array}{l}\text { Failure } \\
\text { Mode }\end{array}$} & \multirow{2}{*}{$\begin{array}{c}\text { Failuse } \\
\text { Mechanisme } \\
\end{array}$} & \multirow{2}{*}{$\begin{array}{l}\text { Detection of } \\
\text { Failure }\end{array}$} & \multirow{2}{*}{ Local } & \multirow{2}{*}{ System } & & & \\
\hline $\mathbb{D}$ & Component & & & & & & & & & \\
\hline 20804 & Separator & $\begin{array}{l}\text { Memisahkan bahan bakar yang } \\
\text { masih bercampur antara minyak } \\
\text { dan juga air sebelum dialirkan ke } \\
\text { service tank atau ke tangki } \\
\text { harian }\end{array}$ & $\begin{array}{l}\text { Tidak mampu } \\
\text { menyaring dengan } \\
\text { baik }\end{array}$ & $\begin{array}{l}\text { Kain kasa } \\
\text { pemeriksaan } \\
\text { pada } \\
\text { separator } \\
\text { rusalk }\end{array}$ & $\begin{array}{l}\text { Diadasan } \\
\text { pemeriksaan } \\
\text { secara berkala } \\
\text { "setiap 500/jam" }\end{array}$ & $\begin{array}{l}\text { Aliran bahan } \\
\text { bakas } \\
\text { terganggul }\end{array}$ & $\begin{array}{l}\text { Performance } \\
\text { Menurun }\end{array}$ & Frequent & Major & $\begin{array}{l}\text { Kondisi kain kasa } \\
\text { perlu diperhatikan } \\
\text { langkah utama } \\
\text { dicuci dan } \\
\text { dibersihkan } \\
\text { minimal 100/jam }\end{array}$ \\
\hline
\end{tabular}


Tabel 5. FMEA Sub Sistem Penyaringan Bahan Bakar

\begin{tabular}{|c|c|c|c|c|c|c|c|c|c|c|}
\hline \multirow{2}{*}{\multicolumn{2}{|c|}{$\begin{array}{c}\text { DESCRIPTION OF } \\
\text { UNIT }\end{array}$}} & \multirow{3}{*}{ FUNCTION } & \multicolumn{3}{|c|}{ DESCRIPTION OF FAILURE } & \multicolumn{2}{|c|}{ EFFECT OF FAILURE } & \multirow{3}{*}{$\begin{array}{c}\text { FAIlURE } \\
\text { RATE }\end{array}$} & \multirow{3}{*}{$\begin{array}{l}\text { SEVERITY } \\
\text { RANGKING }\end{array}$} & \multirow{3}{*}{$\begin{array}{c}\text { RISK } \\
\text { REDUCTING } \\
\text { MEASURES }\end{array}$} \\
\hline & & & \multirow{2}{*}{$\begin{array}{c}\text { Failure } \\
\text { Mode } \\
\end{array}$} & \multirow{2}{*}{$\begin{array}{c}\text { Failure } \\
\text { Mechanisme }\end{array}$} & \multirow{2}{*}{$\begin{array}{c}\text { Detection of } \\
\text { Failure }\end{array}$} & \multirow{2}{*}{ Local } & \multirow{2}{*}{ System } & & & \\
\hline ID & Component & & & & & & & & & \\
\hline \multirow[t]{2}{*}{20805} & \multirow[t]{2}{*}{ Filter } & \multirow[t]{2}{*}{$\begin{array}{l}\text { Menyaring bahan bakar dari } \\
\text { kotoran-kotoran yang dapat } \\
\text { disebabkan oleh partikel-partikel } \\
\text { yang berasal dari tangki induk }\end{array}$} & $\begin{array}{l}\text { Elemen filter } \\
\text { tersumbat }\end{array}$ & $\begin{array}{l}\text { Partikel } \\
\text { kotoran pada } \\
\text { bahan bakar }\end{array}$ & $\begin{array}{l}\text { Diadakan } \\
\text { pemeriksaan } \\
\text { secara berkala }\end{array}$ & $\begin{array}{l}\text { Aliran bahan } \\
\text { bakar } \\
\text { terganggu }\end{array}$ & $\begin{array}{l}\text { Performance } \\
\text { menurun }\end{array}$ & Frequent & Major & $\begin{array}{l}\text { Dilakukannya } \\
\text { kegiatan } \\
\text { pembersihan pada } \\
\text { filter }\end{array}$ \\
\hline & & & $\begin{array}{l}\text { Kerusakan } \\
\text { packing pada } \\
\text { filter }\end{array}$ & $\begin{array}{l}\text { Umur } \\
\text { peralatan }\end{array}$ & \begin{tabular}{|l} 
Diadakan \\
pemeriksaan \\
secara berkala
\end{tabular} & $\begin{array}{l}\text { Kebocoran } \\
\text { pada filter }\end{array}$ & $\begin{array}{l}\text { Kerja sistem } \\
\text { terganggu }\end{array}$ & Frequent & Major & $\begin{array}{l}\text { Melakukan } \\
\text { pengoperasian sampai } \\
\text { filter mengalami } \\
\text { kerusakan, hal ini } \\
\text { lebih efektif } \\
\text { diakibatkan packing } \\
\text { filter sudah mengalami } \\
\text { keausan sehingga } \\
\text { tidak ekonomis jika } \\
\text { langsung mengganti } \\
\text { filter }\end{array}$ \\
\hline
\end{tabular}

Tabel 6. FMEA Sub Sistem Penyaringan Bahan Bakar

\begin{tabular}{|c|c|c|c|c|c|c|c|c|c|c|}
\hline \multirow{2}{*}{\multicolumn{2}{|c|}{$\begin{array}{c}\text { DESCRIPTION OF } \\
\text { UNIT }\end{array}$}} & \multirow{3}{*}{ FUNCTION } & \multicolumn{3}{|c|}{ DESCRIPTION OF FAILURE } & \multicolumn{2}{|c|}{ EFFECT OF FAILURE } & \multirow{3}{*}{$\begin{array}{l}\text { FALURE } \\
\text { RATE }\end{array}$} & \multirow{3}{*}{$\begin{array}{l}\text { SEVERITY } \\
\text { RANGKING }\end{array}$} & \multirow{3}{*}{$\begin{array}{c}\text { RISK } \\
\text { REDUCTING } \\
\text { MEASURES }\end{array}$} \\
\hline & & & \multirow{2}{*}{$\begin{array}{l}\text { Failure } \\
\text { Mode } \\
\end{array}$} & \multirow{2}{*}{$\begin{array}{c}\text { Failure } \\
\text { Mechanisme }\end{array}$} & \multirow{2}{*}{$\begin{array}{c}\text { Detection of } \\
\text { Failure }\end{array}$} & \multirow{2}{*}{ Local } & \multirow{2}{*}{ System } & & & \\
\hline $\mathrm{D}$ & Component & & & & & & & & & \\
\hline 20806 & $\begin{array}{l}\text { Feed } \\
\text { Pump }\end{array}$ & $\begin{array}{l}\text { Mengalirkan bahan bakar } \\
\text { kerumah pompa injeksi }\end{array}$ & Kotor & $\begin{array}{l}\text { Partikel } \\
\text { kotoran }\end{array}$ & & $\begin{array}{l}\text { Penyaluran } \\
\text { bahan bakar } \\
\text { kedalam rumah } \\
\text { pompa injeksi } \\
\text { kurang efektif }\end{array}$ & $\begin{array}{l}\text { Performance } \\
\text { menurun }\end{array}$ & Frequent & Major & $\begin{array}{l}\text { Dilakukan } \\
\text { Pembersihan }\end{array}$ \\
\hline
\end{tabular}

Tabel 7. FMEA Sub Sistem Penginjeksian Bahan Bakar

\begin{tabular}{|c|c|c|c|c|c|c|c|c|c|c|}
\hline \multirow{2}{*}{\multicolumn{2}{|c|}{$\begin{array}{c}\text { DESCRIPTIONOF } \\
\text { UNT }\end{array}$}} & \multirow{3}{*}{ FUNCTION } & \multicolumn{3}{|c|}{ DESCRIPTIONOF FAILURE } & \multicolumn{2}{|c|}{ EFFECT OF FALURE } & \multirow{3}{*}{$\begin{array}{l}\text { FAILURE } \\
\text { RATE }\end{array}$} & \multirow{3}{*}{$\begin{array}{l}\text { SEVERITY } \\
\text { RANGKING }\end{array}$} & \multirow{3}{*}{$\begin{array}{c}\text { RISK } \\
\text { REDUCTING } \\
\text { MEASURES }\end{array}$} \\
\hline & & & \multirow{2}{*}{$\begin{array}{l}\text { Failure } \\
\text { Mode }\end{array}$} & \multirow{2}{*}{$\begin{array}{c}\text { Failure } \\
\text { Mechanisme }\end{array}$} & \multirow{2}{*}{$\begin{array}{l}\text { Detection of } \\
\text { Failuse }\end{array}$} & \multirow{2}{*}{ Local } & \multirow{2}{*}{ System } & & & \\
\hline $\mathbb{D}$ & Component & & & & & & & & & \\
\hline 20807 & $\begin{array}{l}\text { Fuel } \\
\text { Injection } \\
\text { Line }\end{array}$ & $\begin{array}{l}\text { Pipa aliran bahan bakar yang } \\
\text { masuk ke injektor }\end{array}$ & $\begin{array}{l}\text { Aliran pipa } \\
\text { bocor }\end{array}$ & Karat & $\begin{array}{l}\text { Dilakukan } \\
\text { perawatan } \\
\text { secara berkala }\end{array}$ & $\begin{array}{l}\text { Kehilangan } \\
\text { daya isap } \\
\text { pada pompa }\end{array}$ & $\begin{array}{l}\text { Kapasitas } \\
\text { aliran bahan } \\
\text { bakas } \\
\text { berkurang }\end{array}$ & Probable & Major & $\begin{array}{l}\text { Dilakukannya } \\
\text { kegiatan monitoring } \\
\text { terhadap } \\
\text { kemungkinan } \\
\text { terjadinya } \\
\text { kebocoran }\end{array}$ \\
\hline
\end{tabular}




\subsection{Analisis Kuantitatif}

Dalam penelitian ini digunakan sofware Weibull ++ versi 7.0. dengan mengimput data jam operasi komponen berdasarkan log book kapal KMP Bontoharu akan diperoleh secara otomatis distribusi Weibull yang menghasilkan kurva probability density function dan falure rate, serta parameter bentuk $(\beta)$, parameter skala $(\eta)$, parameter lokasi $(\gamma)$. Ketiga nilai parameter tersebut digunakan untuk memperoleh nilai indeks probability density function (PDF), failure rate $(\gamma)$, dan mean time to failure (MTTF)untuk setiap komponen. Berikut salah satu hasil dari running program untuk komponen

\subsubsection{Separator}

Berdasarkan data jam operasi komponen separator $(1307,558,2497,2175,565,502)$ jam, maka dapat diketahui indeks keandalan dari PDF, dimana:

$\beta=$ Parameter bentuk dari distribusi Weibull

$=1,1814$

$\eta=$ Parameter skala dari distribusi Weibull

$=1362.7153 \mathrm{jam}$

$\gamma=$ Parameter lokasi dari distribusi Weibull $=0,9042$

Sehingga:

$f(1307)=\frac{1.1814}{1362.7153}\left(\frac{1307-0,9042}{1362.7153}\right)^{1.1814-1} \times$

$$
2,718^{-\left(\frac{1307-0,9042}{1362.7153}\right) 1.1814}=0,000332
$$

Nilai keandalan dari komponen separator berdasarkan distribusi Weibull adalah sebagaiberikut:

$$
\begin{aligned}
R(1307) & =2,718^{-\left(\frac{1307-0,9042}{1362.7153}\right)^{1.1814}} \\
& =0,386
\end{aligned}
$$

Nilai laju kegagalan pada komponen separator berdasarkan distribusi Weibull adalah sebagai berikut:

$$
\begin{aligned}
& \lambda(t)=\frac{f(t)}{r(t)}=\frac{\beta}{\eta}\left(\frac{t-\gamma}{\eta}\right)^{\beta-1} \\
& \lambda(1307)=\frac{1.1814}{1362.7153}\left(\frac{1307-0,9042}{1362.7153}\right)^{1.1814-1}
\end{aligned}
$$

$=0,00086$

Nilai MTTF untuk komponen separator berdasarkan persamaan dari distribusi Weibulladalah sebagai berikut:

$$
\begin{aligned}
t=m= & M T T F=\eta+\gamma \\
& =1362,6550 \text { jam }+0,9042 \text { jam } \\
& =1363 \text { jam }
\end{aligned}
$$

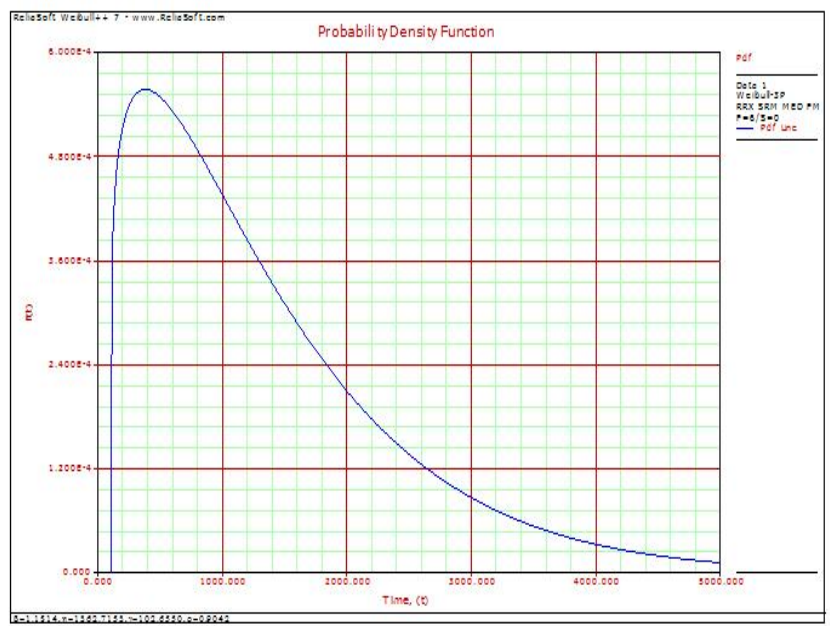

Gambar 3 Grafik Probability density function separator

\subsubsection{Filter}

Berdasarkan data jam operasi komponen filter $(250,208,257,236,187,299,481,425,838$, 915,495,194,313,754,691,474,264,292,285,78

9, 243,215,257) jam, maka dapat diketahui indeks keandalan dari PDF, dimana:

$\beta=$ Parameter bentuk dari distribusi Weibull

$=0,8605$

$\eta=$ Parameter skala dari distribusi Weibull

$=217,8481$ jam

$\gamma=$ Parameter lokasi dari distribusi Weibull $=0,9888$

Sehingga:

$f(250)=\frac{0,9181}{222,4970}\left(\frac{250-0,9888}{222,4970}\right)^{0,9181-1} 2,718-\left(\frac{250-0,9888}{222,4970}\right)^{0,9181}$

$=0,00136$

Nilai Keandalan dari komponen filter berdasarkan distribusi Weibull adalah sebagai berikut: 


$$
\begin{aligned}
R(250) & =2,718^{-\left(\frac{250-0,988}{222,497}\right)^{0,918}} \\
& =0,3299
\end{aligned}
$$

Nilai laju kegagalan pada komponen filter berdasarkan distribusi Weibull adalah sebagai berikut:

$$
\begin{aligned}
\lambda(t) & =\frac{f(t)}{r(t)}=\frac{\beta}{\eta}\left(\frac{t-\gamma}{\eta}\right)^{\beta-1} \\
\lambda(250) & =\frac{0,9181}{222.4970}\left(\frac{250-0,9888}{222.4970}\right)^{0,9181-1} \\
& =0,0041222
\end{aligned}
$$

Nilai MTTF untuk komponen filter berdasarkan distribusi Weibull adalah sebagai berikut:

$$
\begin{aligned}
\bar{t}=m= & M T T F=\eta+\gamma \\
& =222,4970 \mathrm{jam}+0,9888 \text { jam } \\
& =223,48 \text { jam }=223 \text { jam }
\end{aligned}
$$

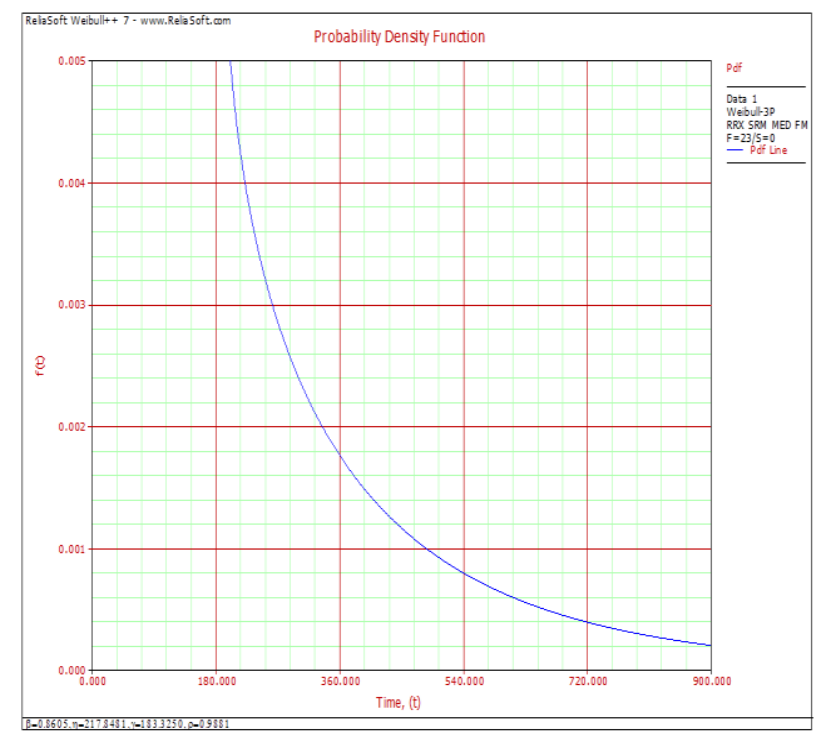

Gambar 4 Grafik Probability density functionfilter

\subsubsection{Pipa}

Berdasarkan data jam operasi komponen pipa $(2508,4181)$ jam, maka dapat diketahui indeks keandalan dari PDF, dimana:

$\beta=$ Parameter bentuk dari distribusi Weibull

$=2,4384$

$\eta=$ Parameter skala dari distribusi Weibull $=3799,553 \mathrm{jam}$ $\gamma=$ Parameter lokasi dari distribusi Weibull $=1$

Sehingga:

$$
\begin{aligned}
f(2508)= & \frac{2.438}{3799.553}\left(\frac{2508-1}{3799.553}\right)^{2,438-1} \times \\
& 2,718^{-\left(\frac{2508-1}{3799.553}\right)^{2.438}}=0,0002454
\end{aligned}
$$

Nilai Keandalan dari komponen pipa berdasarkan distribusi Weibull adalah sebagai berikut:

$$
R(2508)=2,718^{-\left(\frac{2508-1}{3799553}\right)^{2.438}}
$$$$
=0,6957
$$

Nilai laju kegagalan pada komponen pipaberdasarkan distribusi Weibull adalah sebagai berikut :

$$
\begin{aligned}
& \lambda(t)=\frac{f(t)}{r(t)}=\frac{\beta}{\eta}\left(\frac{t-\gamma}{\eta}\right)^{\beta-1} \\
& \begin{aligned}
\lambda(2508) & =\frac{2.4384}{3799.5536}\left(\frac{2508-1}{3799.5536}\right)^{2.4384-1} \\
& =0,0041222
\end{aligned}
\end{aligned}
$$

Nilai MTTF untuk komponen pipa berdasarkan distribusi Weibull adalah sebagai berikut :

$$
\begin{aligned}
\bar{t}=m=M T & \\
& =3799,5536 \mathrm{jam}+1 \mathrm{jam} \\
& =3800 \mathrm{Jam}
\end{aligned}
$$

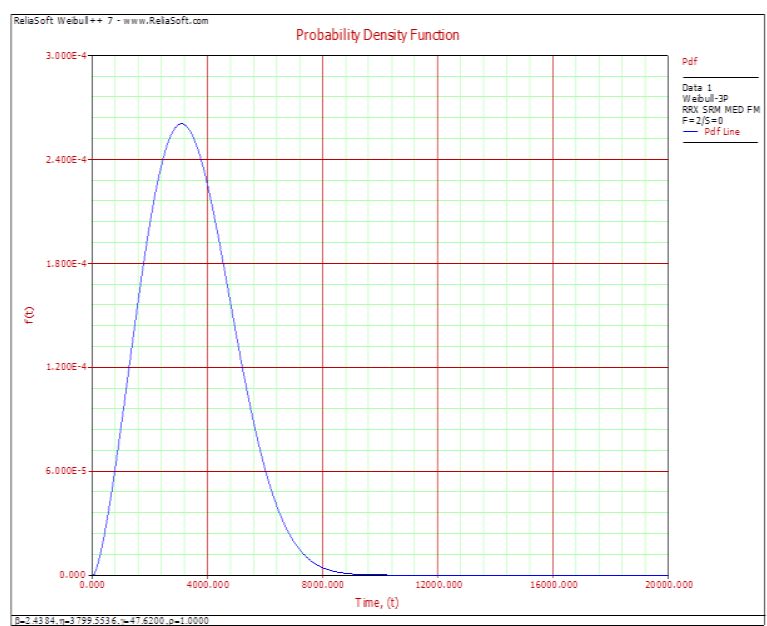

Gambar 5 Grafik Probability density function pipa 


\section{Kesimpulan}

Berdasarkan pendekatan analisa kualitatif dengan metode FMECA dan FTA, diketahui bahwa komponen yang dianggap rawan dan memiliki tingkat resiko paling tinggi yaitu filter dan separator. Sedangkan waktu untuk melakukan kegiatan perawatan untuk tiap komponan sebagai berikut: Filter memiliki nilai laju keandalan yaitu 194 jam operasi. Separator memiliki laju kenadalan yaitu 502 jam operasi. Pipa memiliki laju keandalan yaitu 2.508 jam operasi. Tangki induk dan tangki harian, data perawatan yang sudah diperoleh sudah continue jadi dianggap jadwal perawatannya teratur yaitu sekali setahun. pompa transfer, pompa injeksi, dan feed pump memiliki jadwal perawatan yang sudah dilakukan secara continue dan teratur, yaitu setiap sebulan sekali. Fuel injector, fuel line injector memiliki jadwal perawatan yang sudah dilakukan secara continue dan teratur yakni setiap sebulan sekali. Pada valve tidak diperoleh data perawatan maka komponen dianggap tidak pernah mengalami kerusakan.

\section{Saran}

Berdasarkan kesimpulan diatas maka disarankan :

1. Mempertahankan fungsi dari system bahan bakar dengan dilakukannya kegiatankegiatan perawatan pada tiap komponen, sub sistemnya seperti pemeriksaan, pembersihan, atau perbaikan pada tiap komponen dengan waktu (jam operasi) secara teratur dan berkala

2. Pemilik kapal dalam hal ini operator untuk mencatat atau mendata secara lengkap semua jenis perawatan baik waktu, lama perbaikan, jumlah perbaikan, serta spesifikasi tiap komponen pada sebuah sistem agar dapat secapat mungkin diprediksi perilaku untuk tiap komponen yang akan datang

\section{Daftar Pustaka}

[1] E. S. Hadi, dan U. Budiarto. Analisa Keandalan Sistem Bahan Bakar Motor Induk pada KM. Leuser. Kapal, vol. 5, no. 2, pp. 123-135, 2008.

[2] D. Kececioglu. Realiability Engineering Handbook, vol. 2, Destech Publications, inc, Lancaster, Pennsylvania 17601, U.S.A, 2002.

[3] Alwi, R. Reliability Centered Maintenance dalam Perawatan FO Service Pump Sistem Bahan Bakar Kapal Ikan. Jurnal Riset Teknologi Kelautan, vol. 14, no. 1, 2016.

[4] R. Ramakumar., Engineering Reliability Fundamental and Applications, Prentice-Hall Inc, Oklahoma State University Stillwater, Oklahoma, 1993.

[5] A. K. Buda. Pendahuluan Kuliah Kehandalan Sistem, Handout Kuliah Kehandalan Sistem, Jurusan Teknik Sistem Perkapalan, ITS, 2005. 